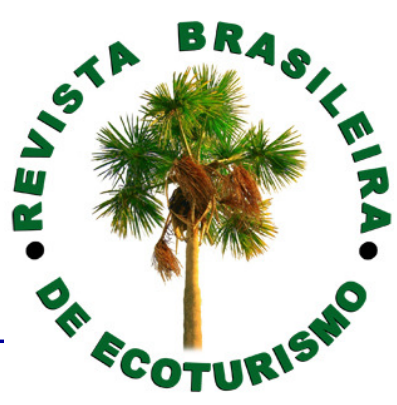

\title{
Aeroporto: suas relações e identidade
}

\author{
Airport: their relationships and identity
}

Fernanda Favorito

\begin{abstract}
RESUMO
Atualmente um aeroporto é muito mais do que apenas um local de passagem com exclusiva finalidade de promover, através de sua infraestrutura, o transporte de passageiros e carga. A infraestrutura aeroportuária tem papel importante nas atividades políticas, econômicas e sociais de um Estado e esta importância deve ser examinada no que se refere à utilidade política e econômica para a sociedade. Em muitos casos, devido ao crescimento desordenado das cidades, os aeroportos passaram a estar situados em regiões de alta concentração urbana, trazendo não apenas benefício como transtornos. O aeroporto ainda pode ser considerado sobre o ponto de vista do Não-lugar, proposto por Augé (1994), entretanto neste trabalho, de caráter exploratório e bibliográfico, pretende-se mostrar que os viajantes e cidadãos de uma cidade podem se identificar e relacionar com 0 aeroporto.
\end{abstract}

PALAVRAS-CHAVE: Aeroporto; Cidade; Identidade; Lugar.

\section{ABSTRACT}

Currently the airport is much more than just a place of passage with sole purpose of promoting, through its infrastructure, the transport of passengers and cargo. The airport infrastructure has an important role in political activities, economic and social importance and that a state must be examined in relation to political and economic usefulness to society. In many cases, due to overcrowded cities, airports began to be located in areas of high urban concentration, bringing not only benefit as disorders. The airport can still be considered under the viewpoint of non-place, proposed by Augé (1994), however this work was exploratory and bibliographical is intended to show that travelers and citizen of a city can identify and relate with the airport.

KEYWORDS: Airport; City; Identity; Place. 


\section{O aeroporto contemporâneo}

A infraestrutura aeroportuária concentra boa parte do tráfego entre pessoas, cargas de alto valor agregado, também, é área de segurança nacional, importante recolhedor de taxas e tributos e, em sua versão mais moderna, fator de desenvolvimento para lugares. Deve-se ainda apontar a importância do aeroporto sendo no comercio internacional, peça chave "a medida que as economias tornam-se cada vez mais abertas e inter-relacionadas" (VASCONCELLOS, 2007). O aeroporto passa a não ser isolado da sociedade passando a ter participação em seu dia a dia e consequentemente se relacionado com esta. Os viajantes também se relacionam com o aeroporto, no momento em que possam haver atos genuínos de hospitalidade ou rituais de passagem.

Silva (1991) afirma que o aeroporto é um local onde existe a transferência entre modais, sendo assim, é necessário que haja sistemas de recepção e meios de acesso para a transferência entre modais.

Autores como Harvey (2001), Guller e Guller (2002) elaboraram um novo conceito sobre o que seria um aeroporto. Os autores afirmam que o aeroporto precisa adaptar-se a nova realidade das nações. Dessa, o aeroporto depende de uma estrutura onde os usuários sintam-se convidados a utilizar seus serviços, que devem atender as crescentes demandas de passageiros. Atualmente, a arquitetura aeroportuária é voltada para que o passageiro permaneça o maior tempo possível em suas instalações e também estende seus serviços a usuários que não são usuários do transporte aéreo.

Segundo Teixeira e Amorim (2005, apud VASCONCELLOS, 2007), a construção de um aeroporto é de grande importância para cidades e estados, sendo que em muitos casos o Estado assume a administração, entretanto, isso passa por afetar sua imagem, definição de atividades e planejamento, sendo assim, uma administração única seria inviável. Por outro lado a infraestrutura também não poderia ser provida unicamente pelo mercado, sendo, este, um meio de resguardar e direcionar o bem comum. Sendo assim, embora restrito as fases de planejamento, licitações e concessão, o Estado tem participação ativa na realização da obra.

A administração privada tem o lucro como seu objetivo principal, sendo assim, direciona seus esforços para a gestão dos negócios, o que acaba por gerar uma grande mudança na "fisionomia aeroportuária", sendo uma dessas alterações mais visíveis o aproveitamento do perímetro para instalação de empreendimentos relacionados indiretamente a atividade, como hotéis, escritórios, terminais de transbordo de cagas que necessitem agilidade no transporte de seus produtos (VASCONCELLOS, 2007).

\section{Os aeroportos e suas relações com as cidades}

Além de serem elos de conexão e integração, os aeroportos, são, também, elementos marcantes da infraestrutura de qualquer cidade, principalmente pela pressão 
que exercem na demanda por serviços e infraestrutura urbana, o que acaba por gerar novos vetores de desenvolvimento ou consolida tendências já existentes (CALDAS, 2008).

O espaço é teorizado como uma estrutura das cidades, sendo conceituado da seguinte forma: "a organização do espaço é também uma forma, um resultado objetivo de uma multiplicidade de variáveis atuando através da história, em que sua inércia passa a ser dinâmica" (SANTOS, 2005, p.45), onde podemos concluir que o espaço é móvel.

Desta forma podemos caracterizar a sensação de movimento urbano e suas implicações para a cidade como relações sociais que que não se rompem, apenas vão se renovando no tempo e no espaço, assim, as cidades são espaços em contínuo processo de reprodução (ORTIGOZA, 1996).

Com o crescimento desordenado das cidades, as áreas no entorno do aeroporto passaram a ser ocupadas tanto para fins residenciais quanto industriais. Os aeroportos trazem uma série de benefícios às cidades, como foi discutido anteriormente, entretanto, também impõe uma série de restrições e incômodos para as cidades, especialmente para sua vizinhança.

A infraestrutura aeroportuária, bem como sua operação necessita acompanhamento de potenciais conflitos entre o aeroporto, meio ambiente e comunidade. Os conflitos associados a a relação entre o aeroporto e a cidade são, geralmente, relacionados ao ruído das aeronave, agregando novos fatores, enfatizando os impactos ambientas, conflitos de vizinhança, aspectos de acessibilidade. Dessa forma a administração exige esforço compartilhado dos setores responsáveis em diversas esferas, com o objetivo de obter um planejamento integrado e cooperativo entre as partes (CALDAS, 2008).

\begin{abstract}
Na perspectiva de assegurar essa integração [aeroporto-cidade], e por consequência, o relacionamento harmônico [...], os Planos de Integração Operacional Urbana, que vêm sendo propostos pela Infraero para retomada das ações voltadas para integração dos aeroportos com sua área de entorno, sugerem, com base no mapeamento das principais etapas identificadas para proposição de ações cooperativas, determinar processos e estabelecer condições para complementação da atividade de planejamento com a de gestão integrada e participativa (CALDAS, 2008, p.329).
\end{abstract}

O Plano de Integração Urbana da Infraero prevê ações relacionadas ao controle de solo, acessibilidade e avaliação do potencial econômico regional, além de medidas de controle de riscos dentro e fora do perímetro aeroportuário. tes áreas:

Segundo Caldas (2008 p.331) o Plano de Integração Urbana atua nas seguin- 
Uso do solo: Considera o incômodo relacionado ao ruído aeronáutico e a necessidade de preservação das áreas de proteção operacional e de controle de riscos de acidentes.

Acessibilidade e Integração Modal: As condições de acessibilidade e complementação modal interferem diretamente no nível de serviço prestado pelo aeroporto, tanto para o segmento de passageiros quanto para a carga aérea.

Aspectos Econômicos e Gerenciais: Independente da alavancagem da economia local/regional, os aeroportos precisam assegurar estratégias próprias de sustentabilidade econômica e financeira.

\section{Conceito de hospitalidade}

Segundo Grinover (2002), a palavra hospitalidade pode ser entendida como recepção de hóspedes, visitantes, viajantes, podendo ser simplificada no ato de bem receber. A hospitalidade ainda implica na relação entre um ou mais hóspedes, sendo a recepção inserida nessa organização e no modo de funcionamento existente.

Para Gotman (2001), a hospitalidade é considerada o ato de acolher e servir alguém que esteja fora de seu local de domicílio, sendo resumida na relação entre aquele que recebe e aquele que é recebido por alguém.

Lashley e Morrison (2004) define a hospitalidade como concebida em um conjunto de comportamentos que se originaram na própria base da sociedade e a hospitalidade envolve a mutualidade e troca e através disso, sentimentos de altruísmo e beneficência.

A troca seria, portanto, o princípio básico da hospitalidade e a troca de um tom cria uma dependência recíproca entre as partes. Ao mesmo tempo em que é voluntário, o dom também é obrigatório, pois quem dá assume uma postura de superioridade e quem recebe possuiu um sentimento de gratidão e sente-se obrigado a retribuir. Diante disto, surge a tríplice obrigação do dar, receber e retribuir (MAUSS, 1974).

\section{Ritual no turismo}

Camargo (2008) afirma que o turista não viaja sem ter sido, de alguma forma, convidado a visitar o local, seja, através de amigos que precedem e deixam uma mensagem de "volte" e que o turista será bem recebido.

O viajante ainda pode optar por ter maior ou menor envolvimento e afinidade com o local, conforme é relatado:

Posso decidir de várias formas. Posso optar pela torre de marfim do pacote e aí minha mensagem é clara - não quero me envolver, quero ter o menor trabalho possível com as culturas locais, quero alguém que ajude a todos os 
momentos - e há aí um claro desejo de encerrar o vínculo, com o pagamento, trazendo todas as imagens que se puder obter e, também aí, encerrar o vinculo com o pagamento. Posso, também, optar por viajar sozinho, com o menor apoio possível do local de origem e de chegada, o que significa que estou ao menos disposto a conhecer e resolver meus problemas de afinidade cultural com os locais. Posso optar por um meio de hospedagem, como um Albergue da Juventude, como que aceitando uma nova dádiva dos locais que é o de criar condições para conhecer outras pessoas como eu. À exceção do primeiro caso, todos os demais têm na grade que se desenha com o dar-receber -retribuir um formidável e rico esquema explicativo, que pode retirar da banalidade e mostrar o real significado das peripécias vividas pelos locais e pelos viajantes (CAMARGO, 2008 p.39-40)

Gotman (2008) afirma que os rituais de turismo são apenas encenações, entretanto, segundo Telfer (2004, p.63) afirma que é possível a existência da hospitalidade ainda que esta seja paga, uma vez que

se um hospedeiro comercial atende bem aos seus hóspedes, com um interesse autêntico por sua felicidade, cobrando um preço razoável, não extorsivo, por aquilo que oferece, suas atividades poderão ser chamadas de hospitaleiras.

\section{Não lugar}

Em sua obra, Augé (1994) descreve inicialmente o conceito do lugar antropológico como um lugar de identificação cultural e histórica, onde um individuo encontrase com sua própria origem e descobre seu lugar na sociedade.

Reservamos o termo "lugar antropológico" àquela construção concreta e simbólica do espaço que não poderia dar conta, somente por ela, das vicissitudes e contradições da vida social, mas à qual se referem todos aqueles a quem ela designa um lugar, por mais humilde e modesto que seja. [...], é simultaneamente princípio de sentido para aqueles que o habitam e princípio de inteligibilidade para quem o observa (AUGÉ,1994, p.50).

Ainda em relação ao lugar antropológico faz parte da coletividade e do individuo reafirmando sua importância pois nele se situa as regras e hábitos de uma sociedade como também a historia de um individuo. São "lugares cuja análise faz sentido, porque foram investidos de sentido, e porque cada novo percurso, cada reiteração trivial, conforta-os e confirma sua necessidade" (AUGÉ, 1994 p.51).

Augé (1994 p.51) ainda afirma que

esses lugares têm pelo menos três características comuns. Eles se pretendem identitários, relacionais e históricos. O projeto da casa, as regras da residência, os guardiões da aldeia, os altares, as praças públicas, o recorte das terras correspondem para cada um a um conjunto de possibilidades, prescrições e proibições cujo conteúdo é, ao mesmo tempo, espacial e social. 
Em contrapartida ao lugar antropológico surge o não lugar, fruto da supermodernidade que, "não pode se definir nem como identitário, nem como relacional, nem como histórico" (AUGÉ, 1994. p.72). Esse não lugar e fruto de

\begin{abstract}
um mundo assim prometido à individualidade solitária, à passagem, ao provisório e ao efêmero [...]. O lugar e o não-lugar são, antes, polaridades fugidias: o primeiro nunca é completamente apagado e o segundo nunca se realiza totalmente - palimpsestos em que se reinscreve, sem cessar, o jogo embaraIhado da identidade e da relação. Os não-lugares, contudo, são a medida da época; medida quantificável e que se poderia tomar somando, mediante algumas conversões entre superfície, volume e distância, [..]"meios de transporte" [..], os aeroportos, as estações e as estações aeroespaciais, as grandes cadeias de hotéis, os parques de lazer, e as grandes superfícies da distribuição [..] que mobilizam o espaço extraterrestre para uma comunicação tão estranha que muitas vezes só põe o indivíduo em contato com uma outra imagem de si mesmo AUGÉ (1994 p. 73).
\end{abstract}

Desta forma o não lugar e visto como um lugar onde não se estabelece uma ligação identitária, nem rituais ou qualquer acontecimento em que um individuo pode ligar-se a algum acontecimento de sua própria historia. No não lugar os procedimentos são pré-estabelecidos sem nenhuma relação com os indivíduos que nele estão. Sendo assim, Auge (1994) define o espaço do viajante como o arquétipo do não lugar, uma vez que o viajante passa de um ponto ao outro sem tomar um real conhecimento das localidades de um lugar, lugares que são lugares de fato para os moradores, mas que o viajante não percebe, pois não os vive como locais, não tem experiências reais. A experiência do viajante é reduzida a indicações textuais, seja como orientações, ou indicações que determinado local é de fato um lugar com significado histórico. A supermodernidade ignora os lugares em rota para outros lugares.

\begin{abstract}
Muitos prospectos turísticos sugerem um tal desvio, um tal giro do olhar, propondo por antecipação ao amador de viagens a imagem de rostos curiosos ou contemplativos, solitários ou reunidos, que escrutam o infinito do oceano, a cadeia circular de montanhas nevadas ou a linha de fuga de um horizonte urbano repleto de arranha-céus: sua imagem, em suma, sua imagem antecipada, que só fala dele, mas porta um outro nome (AUGÉ, 1994, p.79)
\end{abstract}

Sendo assim constataremos que a experiência do não-lugar como afastamento de si mesmo e colocação à distância simultânea do espectador e do espetáculo nem sempre está ausente disso (AUGÉ, 1994).

Em um não lugar, a individualidade de um indivíduo nunca está em questão, são todos considerados os mesmo, a não ser, em casos, de entrada e saída, onde o indivíduo deve apresentar um documento de identificação, como carteira de identidade, de motorista ou passaporte. Em não lugares, os indivíduos são reduzidos a soli- 
Favorito, F.

dão e similaridade, porque, há uma mínima interação social, a passagem temporal não é marcado por monumentos ou qualquer significado pessoal. Assim, o não lugar minimiza o familiar, o conhecido, o reconhecível, e suspende a identidade, relações e história. O mais marcante de um não lugar é que nunca há um rosto conhecido. Em um lugar, mesmo o rosto de um desconhecido é familiar em termos de carência, uma vez que essa proximidade e identificação é a base a base das relações sociais (AUGÉ, 1994)

\title{
Aeroporto, não lugar e identidade
}

Para Augé (1994), aeroportos são locais de solidão, não criando relação, identidade ou tão pouco história com o viajante. Já para Siqueira e Siqueira (2004, p.17) que realizaram um trabalho no Aeroporto Internacional do Galeão;

\begin{abstract}
No aeroporto são tecidas tramas da vida cotidiana dos que lá trabalham ou dos que viajam a prazer ou por obrigação. O corpo das mulatas sambando nesse ambiente informa a turistas e viajantes que há algo mais ali do que simplesmente solidão e similitude. Espaço no qual sentidos são tecidos, no aeroporto também estão presentes o poder e a política de um Estado que vigia, controla e que é a última porta do estado. Nesse sentido, dádivas, saudações, gestos, mulatas, samba e corpos desnudos formam um discurso simbólico e ideológico construído pelo Estado. Tal discurso seria uma tentativa de fundar uma ordem consensual livre de contradições e antagonismos
\end{abstract}

Siqueira (2006, p.8-9) considera a chegada ao aeroporto se inicia um ritual de passagem, onde o cidadão normal perece e o turista nasce:

\begin{abstract}
Quando turistas e viajantes norte-americanos chegavam ao Rio de Janeiro durante o início do processo de identificação por parte das autoridades brasileiras, em 2004, pelo menos uma parte do processo ritual como passagem já estava em andamento: o momento da separação/saída de sua própria sociedade de origem. Viajar ao Brasil, já implicava em romper com o tempo social normal - o dia-a-dia cotidiano de trabalho - uma das características dos rituais de passagem.
\end{abstract}

Os americanos deveriam passar pela identificação da polícia federal, momento extremamente incerto, uma vez que o visitante não pode adentrar um local sem que antes comprove suas intenções (GENNEP, 1977 apud SIQUEIRA, 2006). Neste momento há o segundo ritual de passagem, o de limiaridade.

Em seguida, os americanos desembarcavam pelo saguão de desembarque internacional onde eram recepcionados, pela segunda vez, por uma comitiva formada por desde membros de uma escola de samba com passistas e mulatas seminuas até representantes do poder público municipal e do Rio Convention's Bureaux. Entre as 
muitas ações gestuais realizadas por esses atores, estavam as de dançar com os americanos, abraçá-los, dizer-lhes palavras de cordialidade e distribuir brindes e presentes (dádivas) (SIQUEIRA, 2006).

Desta forma, o autor conclui que:

Ei- nos diante do ritual de agregação aos americanos que, de um momento hostil, se rever te para o da hospitalidade. Tudo isso se desenrolando dentro do aeroporto, lugar onde identidades são confrontadas, construídas, alteradas e cujos sentidos e significados inundam seus salões (SIQUEIRA, 2006, p.12).

\section{Considerações finais}

Como pudemos perceber, o aeroporto moderno é muito mais do que apenas um local de passagem, sendo de grande importância para a sociedade. $\mathrm{O}$ aeroporto é vetor de desenvolvimento para as cidades e se relaciona com estas de forma intensa. Um grande complexo de serviços se organiza ao redor do aeroporto e este passa a ser gerador de empregos e pagador de tributos. Apesar de todos os benefícios, também existem os problemas trazidos por este, principalmente, à sua vizinhança, no que se diz respeito a queixas sobre o ruído produzido pelas aeronaves. Havendo uma relação entre o aeroporto e as pessoas de uma cidade, cria-se uma um laço, uma relação e identidade entre estes. O aeroporto pode ser visto apenas como um não lugar, conforme proposto por Augé (1994), sendo um local onde não exista história, relação ou identificação ou pode ser considerado como um lugar onde se possa criar identidade e onde os rituais são mais fortes do que poderia imaginar, como é demonstrado no trabalho de Siqueira (2006).

\section{Referências bibliográficas}

AUGÉ, M. Não-lugares: introdução a uma antropologia da supermodernidade. 2.ed.Campinas: Papirus. 2001.

CALDAS, T.C.M. Integração Urbana de Aeroportos, um Desafio para o Planejamento. Anais do 7ํㅗㄴ SITRAER, Rio de Janeiro, p.327-33, TR410, 2008.

CAMARGO, L.O.L. A Pesquisa em Hospitalidade. Revista da Hospitalidade, 2008. p. 15-51.

GOTMAN, A. Le sens de I'hospitalité. Paris: Presses Universitaires de France, 2001.

GOTMAN, A. O turismo e a encenação da hospitalidade. In: BUENO-RAMOS, M.L.; CAMARGO, L.O.L. (orgs). Cultura e consumo: estilo de vida na contemporaneidade. São Paulo: Editora SENAC São Paulo, p.115-134, 2008.

GRINOVER, L. Hospitalidade: um tema a ser reestudado e pesquisado. In: DIAS, C.M. (org). Hospitalidade: reflexões e perspectivas. São Paulo: Manole, 2002. 
GULLER, M; GULLER, M. Del Aeropuerto a la Ciudad Aeropuerto. Editorial Gustavo Gili, Barcelona, 2002.

HARVEY, D. Condição Pós Moderna: Uma Pesquisa Sobre as Origens da Mudança Cultura. Loyola, São Paulo, 2001.

INFRAERO. Aeroportos Industriais. 2012 Disponível em: <http:// www.infraero.gov.br/index.php/br/aeroportos-industriais/conceito.html> Acesso em 29/05/2012.

KUHN, E.L. Impactos da Competição entre Aeroportos no Brasil. Dissertação de Mestrado. Universidade de Brasília, Brasília, 2003.

LASHLEY, C.; MORRISON, A. Em busca da hospitalidade: perspectivas para um mundo globalizado. São Paulo: Manole, 2004.

MAUSS, M.. Ensaio sobre a dádiva. Forma e razão da troca nas sociedades arcaicas. In: MAUSS, M. Sociologia e Antropologia. v. II. São Paulo : Edusp, 1974.

ORTIGOZA, S.A.G. As franquias e as novas estratégias do comércio urbano no Brasil. Dissertação de Mestrado. Instituto de Geociências e Ciências Exatas, Unesp, Rio Claro, 1996.

SCATOLINI, F.; ELLER; R.A.G. Impacto do Ruído Aeronáutico no Mercado Imobiliário de São Paulo. Anais do 7º SITRAER, Rio de Janeiro, 2008.

SANTOS, M. Da totalidade ao lugar. São Paulo: Edusp, 2005.

SILVA, J.M. Implementação e Desenvolvimento de Aeroportos Industriais. Dissertação (Mestrado em Engenharia de Produção). Universidade Federal de Minas Gerais, Belo Horizonte, 2008.

SILVA, A. Aeroportos e Desenvolvimento. Belo Horizonte: Ed. Villa Rica, 1991.

SIQUEIRA, E.D. Ritual, turismo e cultura: o aeroporto do Galeão como lugar de passagem. Anais do XXIX Congresso Brasileiro de Ciências da Comunicação, Brasília, p. 1-15, 2006.

SIQUEIRA, E.D.; SIQUEIRA, D.C.O. Corpo, mito e imaginário nospostais das praias cariocas. Anais do XXVIII Congresso brasileiro de ciências da comunicaçãoINTERCOM, Rio de Janeiro, UERJ, p. 5-9, 2005.

SIQUEIRA, E.D.; SIQUEIRA, D.C.O. Samba no Galeão: corpo,cultura e representações do Rio de Janeiro. Anais do VIII ENTBL-Encontro Nacional de Turismo com base local, Curitiba,p. 6-13, 2004.

VASCONCELLOS, L.F.S. O aeroporto como Integrante de um Projeto de Desenvolvimento Regional: A Experiência Brasileira. Dissertação (Mestrado em Transportes). Universidade de Brasília, Brasília, 2007. 
Fernanda Favorito: Universidade Anhembi Morumbi, São Paulo, SP, Brasil. Email: fernandafavorito@hotmail.com

Link para o currículo Lattes: http://lattes.cnpq.br/0009729606417098

Data de submissão: 30 de maio de 2012

Data de recebimento de correções: 30 de maio de 2012

Data do aceite: 10 de dezembro de 2012

Avaliado anonimamente 